\title{
The Effect of Altrenogest Treatment Timing and Artificial Lighting on Hastening of Ovulation in Barren Mares
}

\author{
Hasan Basri Tek
}

\begin{abstract}
Background: The mares are seasonally polyestrous animals that regular ovulatory cycles of mares occur together with increasing day length. Exposure of mares to an artificial photoperiod is the most common and predictable technique that it is used to develop follicular activity early in the year. Follicle activity is minimal in mares during two winter months of January and February in Northern Hemisphere. The main objective of this study was to investigate efficacy of artificial lighting and timing of altrenogest treatment for hastening the ovulation in Thoroughbred mares.

Materials, Methods \& Results: One hundred and six Thoroughbred mares had different follicle sizes $(<30 \mathrm{~mm})$ was evaluated under four groups. Mares undergoing only reproductive examination were control group Group I ( $\mathrm{n}=18$ ). The mares has less than $30 \mathrm{~mm}$ in diameter folicle applied oral altrenogest $(0.044 \mathrm{mg} / \mathrm{bw}$, for 10 days $)$ were grouped according to the month of application: Group II [February; $n=16$ ], Group III [March; $n=57$ ] and Group IV [April; $n=15]$. Ultrasonographical examinations performed at the day of admission and repeated twice a week for 15 days. Naturel mating was planned considering to uterine edema ( $>35 \mathrm{~mm}$ folicle size), and pregnancies were determined at 14, 28 and 50th day postovulation. Statisticaly, mean and standard deviations and general linear model procedure was performed on Minitab 17, and Anova was used to analysis of variance. The averages of the major variations were compared with the Tukey's multiple comparison test. The factors effecting to pregnancy rate was analyzed by Chi-square test. Correlations were compared with the Pearson correlation test. The effect of initial months on the size of follicle diameter was found to be significant $(P=0.037)$. Artificial lighting had no effect on the initial follicle diameter $(P=0.919)$. The initial follicle diameter $(P=$ $0.001)$ and artificial lighting $(P=0.026)$ had a significant effect on the time of follicle reaching in $35 \mathrm{~mm}$ diameter. Initial follicle diameter $(P=0.001)$, treatment time $(P=0.000)$, light therapy $(P=0.026)$ and altrenogest application $(P=0.026)$ were found to be effective. Initial follicle diameter $(P=0.575)$, timing of treatment $(P=0.243)$, light therapy $(P=0.461)$ and application of altrenogest $(P=0.088)$ had no significant effect on the diameter of ovulatory follicle. There are positive correlations between the initial follicle diameter and follicle diameter at the end of treatment $(P=0.000 ; \mathrm{R}=0.399)$; There is a high positive correlation between the day of reaching $35 \mathrm{~mm}$ diameter and ovulation day $(P=0.000 ; \mathrm{r}=0.777)$; there is a negative correlation between beginning follicle diameter and $35 \mathrm{~mm}$ diameter $(P=0.006 ; \mathrm{r}=-0.266)$ and ovulation day $(P=0.000 ; \mathrm{r}=-0.366)$. There was a negative correlation between the follicle diameter at the end of the treatment and the $35 \mathrm{~mm}$ diameter $(P=0.000 ; \mathrm{r}=-0.736)$ and the day of ovulation $(P=0.000 ; \mathrm{r}=-0.628)$. These statistical results pointed out that timing of altrenogest treatment and artificial lighting had effectivity on hastening the ovulations in barren mares. Discussion: To evaluate the seasonal effect on follicle diameter, the measurement of the initial follicle diameters is important, which is smaller in February than the following months. The initial follicle diameter is effect on time to reach in 35 mm diameter and ovulation; however, in these mares, ovulation forms in a long time. Regarding the seasonal effect, the success of ovulation depends on treatment time in seasonal months. It is shown that short term altrenogest administration has not shortened interval to the post treatment ovulation. As a limitation of this study, because there are not enough mares in control group, further studies should be planned for more evaluations.
\end{abstract}

Keywords: altrenogest, artificial lighting, baren mare, ovulation, time of treatment.

DOI: $10.22456 / 1679-9216.90350$ 


\section{INTRODUCTION}

The mares are seasonally polyestrous animals that regular ovulatory cycles of mares occur together with increasing day length [4]. Exposure of mares to an artificial photoperiod is the most common and predictable technique that it is used to develop follicular activity early in the year [6]. Follicle activity is minimal in mares during two winter months of January and February in Northern Hemisphere [4]. During anestrus, there is no sexual activity, and mares have limited reproductive potential due to baseline of the hormones $[7,12]$. Most non-pregnant mares are still in the transition period from seasonal anestrus to normal ovulatory estrous cycles [7]. This transition period takes 60 to 80 days in mares. In addition, mares have typical long and irregular estrus behaviors at this period [4,7].

It is well-known that progesterone is an effective hormone, which is administered to advance the first ovulation of the year in mares maintained under a stimulatory artificial photoperiod for 2 months [8-10]. However, some authors have indicated that progesterone therapy is not effective at advancing the first ovulation of the year [1,11]. Although there have been several methods applied to advance the onset of normal ovulatory estrous cycles in transitional mares [6], numerous studies are planned to evaluate the efficacy of both natural progesterone and synthetic progestin on management of the anovulatory season $[9,12]$.

The purpose of the present study was therefore to investigate efficacy of artificial lighting and timing of altrenogest treatment for hastening the onset of the breeding season in Thoroughbred mares in the seasonal anovulatory period.

\section{MATERIALS AND METHODS}

Animals

The presented study was conducted by evaluating the records of mares with reproductive examinations in South Marmara region. The materials consisted of barren Thoroughbred mares $(\mathrm{n}=106 ; 5$-14 year-old) with different follicle sizes $(<30 \mathrm{~mm})$, who had no systemic and reproductive abnormality assessed with clinical examinations between February and April. Mares were evaluated under four groups. Mares undergoing only reproductive examination were evaluated as control group (no-treated) Group I [GRI - $(\mathrm{n}=18)]$. In order to hastening the ovulation, the mares applied in the oral altrenogest (Regumate $\left.{ }^{1}\right)^{1}$ [0.044 mg / bw, for 10 days] group according to the month of application Group II [GRII - February; $(\mathrm{n}=16)$ ], Group III [GRIII - March; $(\mathrm{n}=57)$ ] and Group IV [GRIV - April; $(\mathrm{n}=15)$ ].

The mares in each group were divided into two subgroups according to pre-treatment artificial lighting application (being applied or not being applied) for $16 \mathrm{~h}$ day length during a 6-10 week period. The mares having ovulation within 22 days following the administration of altrenogest were evaluated as positive for response to the application.

\section{Examinations}

Ultrasonographical examinations of the mares were performed using a 5.0 MHz linear-array transrectal transducer. From the day of admission, routine reproductive examinations of the mares in all groups and measurement of the diameters of the largest follicle in the ovary were repeated twice a week for 15 days. In this process, the mare with a follicle diameter less than $30 \mathrm{~mm}$ and no corpus luteum were treated with oral altrenogest for 10 days. As a single dose only at day 10, $250 \mu \mathrm{g}$ cloprostenol (PGF2 $\alpha$ analogue) was injected intramuscularly to mares. The follicle diameters of the mares were recorded at the beginning of treatment and at the end of the treatment. In addition, days from the beginning of the treatment to $35 \mathrm{~mm}$ diameter and to ovulation and diameter of ovulatory follicle were recorded. The day before mating the mares were treated either hCG $\left(\text { Chorulon }{ }^{\circledR}\right)^{1}[3,000$ IU, iv.] or GnRH (Receptal $\left.{ }^{1}\right)^{1}[5 \mathrm{~mL}, \mathrm{im}]$.

Mating was by natural service in mares on the basis of uterine edema, which had dominant follicle $(\geq$ $35 \mathrm{~mm}$ ). Pregnancies were determined at 14, 28 and $50^{\text {th }}$ day postovulation.

\section{Statistical analysis}

Mean and standard deviations of the data were calculated in groups, and using general linear model procedure of Minitab statistical analysis program (Minitab 17)2, analysis of variance (Anova) was performed to determine the significant differences among the groups. In this context, the following optimal model was selected;

$$
\mathrm{Y}_{\mathrm{ijkl}}=\mu+\mathrm{L}_{\mathrm{i}}+\mathrm{M}_{\mathrm{j}}+\beta \mathrm{F}_{\mathrm{k}}+\mathrm{e}_{\mathrm{ijkl}}
$$

where: $Y_{i j k l}$ represents the studied traits, $\mu$ is the overall mean, $\mathrm{L}_{\mathrm{i}}$ is the fixed effect of light treatment, $\mathrm{M}_{\mathrm{j}}$ is the fixed effect of starting month of the experimental period, $\beta \mathrm{F}_{\mathrm{k}}$ is the regression effect of initial follicular diameter, $\mathrm{e}_{\mathrm{ijkl}}$ is random error. The averages of the ma- 
jor variation sources were compared with the Tukey's multiple comparison test $(P<0.05)$. The effect of the factors on pregnancy rate was analyzed by Chi-square test. Correlations were compared with the Pearson correlation test $(P<0.01)$.

\section{RESULTS}

Mean and standard deviation values of the follicle diameter at the beginning and at the end of the treatment, interval time between end of the treatment and follicle reaches $35 \mathrm{~mm}$ diameter, the time from the beginning of the treatment to ovulation and diameter of the ovulatory follicle and pregnancy rates are given in Table 1 and ovulation rates were given in Table 2.

The effect of initial months on the size of follicle diameter was found to be significant $(P=0.037)$. The mares in February were found to have a smaller follicle diameter than the mares in March and April, On the other hand, artificial lighting had no effect on the initial follicle diameter $(P=0.919)$.

The initial follicle diameter $(P=0.001)$ and artificial lighting $(P=0.026)$ had a significant effect on the time of follicle reaching in $35 \mathrm{~mm}$ diameter.

About to reaching of the ovulation day, initial follicle diameter $(P=0.001)$, treatment time $(P=$ $0.000)$, light therapy $(P=0.026)$ and altrenogest application $(P=0.026)$ were found to be effective.

Initial follicle diameter $(P=0.575)$, timing of treatment $(P=0.243)$, light therapy $(P=0.461)$ and application of altrenogest $(P=0.088)$ had no significant effect on the diameter of ovulatory follicle.

The pregnancy rates in GRI to GRIV were $72.2 \%$; 50\%; $64.91 \%$ and $60 \%$, respectively. Pregnancy rates did not differ according to the timing of treatment $(P=0.579)$, to artificial lighting $(P=0.489)$, to altrenogest treatment $(P=0.384)$ and diameter of ovulatory follicle $(P=0.344)$.

There are positive correlations between the initial follicle diameter and follicle diameter at the end of treatment $(P=0.000 ; \mathrm{r}=0.399)$; There is a high positive correlation between the day of reaching $35 \mathrm{~mm}$ diameter and ovulation day $(P=0.000 ; \mathrm{r}=0.777)$; there is a negative correlation between beginning follicle diameter and 35 mm diameter $(P=0.006 ; \mathrm{r}=-0.266)$ and ovulation day $(P=0.000 ; \mathrm{r}=-0.366)$. There was a negative correlation between the follicle diameter at the end of the treatment and the $35 \mathrm{~mm}$ diameter $(P=0.000 ; \mathrm{r}=-0.736)$ and the day of ovulation $(P=0.000 ; \mathrm{r}=-0.628)$.

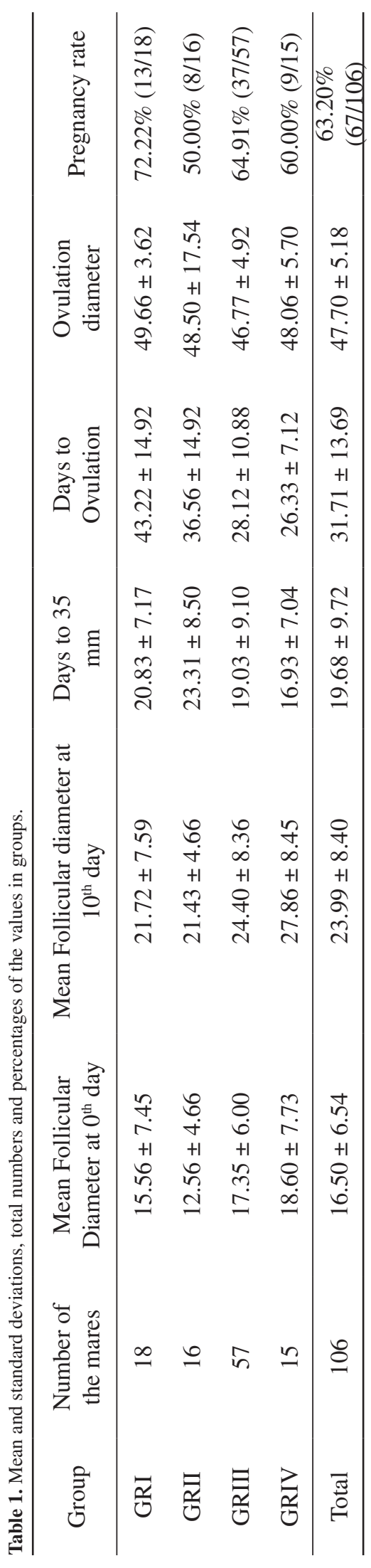


Table 2. The success of ovulation in 22 days and pregnancy rates of groups.

\begin{tabular}{cccc}
\hline Groups & Number of the mares & The success of ovulation in 22 days & Pregnancy rate \\
\hline GRI & 18 & $22.2 \%(4 / 18)$ & $72.22 \%(13 / 18)$ \\
GRII & 16 & $50 \%(8 / 16)$ & $50 \%(8 / 16)$ \\
GRIII & 57 & $71.93 \%(41 / 57)$ & $64.91 \%(37 / 57)$ \\
GRIV & 15 & $80 \%(12 / 15)$ & $60 \%(9 / 15)$ \\
\hline
\end{tabular}

\section{DISCUSSION}

The presented study aimed in Thoroughbred barren mares since artificial lighting and timing of progestin treatments for hastening the onset of the breeding season is still controversial between the practitioners. Thoroughbred breeding season begins at a time when most non-pregnant mares are in the transition phase from winter anestrus to normal, regular estrus cycles [5]. The breeding season in Thoroughbred mares begins about mid-February, and it is important to get early pregnancies at the beginning of the reproductive season, when irregular cycles of mares usually present [12]. Mares in deep anestrus or in transitional phase for a long time are a particular cause of concern and extra work in Thoroughbred stud management [2].

It has been stated that numerous treatments are reported the usage of progesterone or other progestagens for estrous induction in mare, which are the most frequent options [12]. Progesterone and progestagens are often used to manage the transition period in mares [5]. Moreover, progestine treatment folicle activity is much more important than time of year in mare [9]. Considering to these literature information, altrenogest was chosen in this study as a treatment of progestin.

To evaluate the seasonal effect on follicle diameter [9], the measurement of the initial follicle diameters is important, which is smaller in February than the following months. On the other hand, it is well-known that the initial follicle diameter affects the success of the treatment [9]. According to the presented results, the initial follicle diameter was effect on time to reach in $35 \mathrm{~mm}$ diameter and ovulation; however, in these mares, ovulation formed in a long time. Regarding the seasonal effect, it can be informed that success of ovulation depends on treatment time in seasonal months. In March and April, ovulation time was shorter than February and control group.

Ovulation time was also shorter in treatment groups than control group. Similarly, in a previously reported study, ovulations are taken place in 18 day with a percent of $84 \%$ [2]. Contrary to a previous study [3], it is shown that short term altrenogest administration has not shortened interval to the post treatment ovulation. The mean interval to ovulation after the end of treatment with altrenogest is 20.9 days, whereas control 17.1 days. Seven days altrenogest administration does no effect to shortening the interval from completion of the treatment to ovulation.

\section{CONCLUSIONS}

In conclusion, in this study, ovulation of some mares started during treatment; thus, we take the interval from the first day of treatment to ovulation instead of the end of treatment.

As a limitation of this study, because there were not enough mares in control group, further studies should be planned for more evaluations.

\section{MANUFACTURERS}

${ }^{1}$ MSD - Merck Sharp Dohme İlaçları Ltd. Şti. Istanbul,Turkey.

${ }^{2}$ Minitab. State College, PA, USA.

Acknowledgements. The authors would thank to Prof.Dr. Kamil Seyrek Intas, Dr. E.Sinem Ozdemir Salci and Dr. Sena Ardicli for their contributions.

Declaration of Interest. The authors declare no conflict of interest. The author alone is responsible for the content and writing of paper.

\section{REFERENCES}

1 Alexander S.L. \& Irvine C.H.G. 1991. Control of onset of breeding season in the mare and its artificial regulation by progesterone treatment. Journal of Reproduction and Fertility. 44: 307-318. 
2 Allen W.R., Urwin V., Simpson D.J., Greenwood R.E.S., Crowhurst R.C., Ellis D.R., Ricketts S.W., Hunt M.D.N. \& Wingfield Digby N.J. 1980. Preliminary studies on the use of an oral progestogen to induce oestrus and ovulation in seasonally anoestrous Thoroughbred mares. Equine Veterinary Journal. 12: 141-145.

3 Colbern G.T., Squires E.L. \& Voss J.L. 1987. Use of altrenogest and human chorionic gonadotropin to induce normal ovarian cyclicity in transitional mares. Equine Veterinary Journal. 7: 69-72.

4 Ginther O.J. 1992. Reproductive Biology of the Mare: Basic and Applied Aspects. 2nd edn. Cross Plains: Equiservices Publishing, pp.105-172.

5 Hanlon D.W. \& Firth E.C. 2012. The reproductive performance of Throughbred mares treated with intravaginal progesterone at the start of the breeding season. Theriogenology. 77: 952-958.

6 McCue P.M., Logan N.L. \& Magee C. 2007. Management of the transition period: hormone therapy. Equine Veterinary Education. 19: 215-221.

7 Nagy P., Guillaume D. \& Daels P. 2000. Seasonality in mares. Animal Reproduction Science. 60: 245-262.

8 Palmer E. 1979. Reproductive management of mares without detection of oestrus. Journal of Reproduction and Fertility. 27: 263-270.

9 Squires E.L., Stevens W.B., McGlothlin D.E. \& Pickett B.W. 1979. Effect of an oral progestin on the estrous cycle and fertility of mares. Journal of Animal Science. 49: 729-735.

10 Taylor T.B., Pemstein R. \& Loy R.G. 1982. Control of ovulation in mares in the early breeding season with ovarian steroids and prostaglandin. Journal of Reproduction and Fertility. 32: 219-224.

11 Turner D.D., Garcia M.C., Webel S.K. \& Ginther O.J. 1981. Influence of follicular size on the response of mares to allyl trenbolone given before the onset of the ovulatory season. Theriogenology. 16: 73-84.

12 Vizuete G., Diez E., Galisteo J., Agüera E., Aguilera-Tejero E. \& Perez-Marin C.C. 2013. Comparison of different treatments for oestrus induction in seasonally anovulatory mares. Reproduction in Domestic Animals. 48: 463-469. 